\title{
INFLUÊNCIA DE DIFERENTES CONCENTRAÇÕES DE SUBSTRATOS ORGÂNICOS NA PRODUÇÃO DE MUDAS DE COUVE
}

\author{
Géssica da Silva Martins ${ }^{1}$ \\ Ivan da Costa llhéu Fontan ${ }^{2}$ \\ Arnaldo Henrique de Oliveira Carvalho ${ }^{3}$ \\ Fábio Luiz de Oliveira ${ }^{4}$
}

Resumo: Dentre os fatores de maior importância na produção de mudas de hortaliças com a qualidade necessária à formação de lavouras sadias e produtivas está o substrato onde estas mudas serão produzidas Assim, objetivou-se com este estudo avaliar o efeito de diferentes composições e concentrações de substratos orgânicos no desenvolvimento de mudas de couve. O trabalho foi desenvolvido no IFES, Campus Ibatiba, e o experimento estabelecido em um DIC com 8 (oito) repetições, e esquema fatorial $6 X$ 3 (6 composições e 3 concentrações de substratos). Aos 25 dias após a semeadura de couve (Brassica oleracea var. acephala) foram avaliados o diâmetro do colo, a altura total e a massa fresca da parte aérea. Houve efeito significativo na interação composição-concentração. O uso dos compostos de maneira pura ou em mistura com o solo propiciou efeitos positivos sobre o crescimento em altura e acúmulo de massa fresca da parte aérea evidenciando a possibilidade do produtor rural utilizar diferentes materiais disponíveis em sua região na produção de mudas de hortaliças, atendendo aos preceitos da produção orgânica de alimentos, reduzindo custos e otimizando recursos.

Palavras-chave: Brassica oleracea var. acephala; Compostos orgânicos; Mudas de hortaliças.

\footnotetext{
${ }^{1}$ Instituto Federal do Espírito Santo/Campus Ibatiba, Brasil. E-mail: jessyka9inha@gmail.com.

2 Instituto Federal do Espírito Santo/Campus Ibatiba, Brasil. E-mail: ivanfontan.florestal@gmail.com.

3 Instituto Federal do Espírito Santo/Campus Ibatiba, Brasil. E-mail: acarvalho@ifes.edu.br.

${ }^{4}$ Professor - UFES - CCA, Departamento de Fitotecnia. E-mail: fabio.oliveira.2@ufes.br.
} 